РЫБАКОВ Андрей Вячеславович - доктор политических наук, профессор кафедры философии Московского авиационного института (Национальный исследовательский университет) (125993, Россия, г. Москва, ГСП-3, Волоколамское ш., 4, A-80; rybackov@rambler.ru)

КВОН Даниил Андреевич - кандидат политических наук, доцент кафедры философии Московского авиационного института (Национальный исследовательский университет) (125993, Россия, г. Москва, ГСП-3, Волоколамское ш., 4, A-80; docentkvon@yandex.ru)

\title{
РАЗВИТИЕ ЕВРОИНТЕГРАЦИИ: СЦЕНАРНЫЙ АНАЛИЗ
}

Аннотация. Предметом исследования в статье выступают возможные варианты дальнейшей эволюции интеграционного процесса в Европейском союзе (ЕС). Авторы показывают, что кризисные процессы, которые наблюдаются в развитии институтов ЕС, дали толчок не только евроскептицизму, но и интенсивным поискам новых подходов к развитию европейской интеграции. В реальности мы имеем дело со сложным, неоднозначным и даже внутренне противоречивым процессом, который при любых обстоятельствах неправильно изображать только в одном цвете, предрекая некий единый тренд дальнейшего развития. Речь идет о целом ряде возможных вариантов дальнейшей эволюции евроинтеграционного процесса. Выбор между этими вариантами будет в определяющей степени зависеть от уровня политической воли и креативности соответствующих политических сил, способности мыслить стратегически, выходя за узкие рамки видения настоящего и умения тщательно и сбалансированно анализировать весь сложный комплекс факторов, лежащих в основе евроинтеграции.

Ключевые слова: евроинтеграция, Европейский союз, кризис, сценарии развития, дифференцированная интеграция, федерализация, «многоскоростная» Европа, усиленное сотрудничество

$\mathrm{K}$ ризис в еврозоне и всплеск миграционного кризиса 2015-2016 гг. затронули основы европейского проекта и обнаружили недостатки в эффективности и легитимности существующей в ЕС модели демократии. Граждане стран ЕС предъявляют претензии к финансово-экономическим и политическим элитам по поводу экономической рецессии и безработицы, неспособности своевременно предотвратить кризис. Кризис легитимности ЕС сопровождается падением доверия граждан к традиционным массовым партиям и сопровождается ростом симпатий к популистским партиям и движениям, которые успешно пользуются растущим недовольством общественности своим экономическим положением, а также последствиями массовой миграции из стран Ближнего Востока и Африки [Bertoncini 2017].

С другой стороны, наблюдается активизация тех сил, которые видят возможные ответы на кризис легитимности демократической системы на пути усиления наднационального управления через дальнейшее делегирование государственного суверенитета на уровень ЕС в области макроэкономической, социальной, фискальной, внешней, миграционной политики и политики безопасности [The Age of Uncertainty... 2017: 58-59]. Однако решится ли ЕС на реформу своей структуры для преодоления многочисленных кризисов? И приспособлен ли европейский проект для того, чтобы отвечать на вызовы?

Как известно, среди отцов-основателей европейской интеграции после Второй мировой войны не было единого видения того, каким должен быть европейский проект. Христианские демократы К. Аденауэр, А. де Гаспери и Р. Шуман видели единую Европу как конфедерацию, которая обеспечивает мир, оперирует стратегическими вопросами и полностью уважает национальную и региональную автономию. Они благосклонно относились к идентичности и традициям европейских наций и регионов, но в то же время не доверяли сугубо технократическому подходу к развитию интеграции. 
В противоположность им, Ж. Монне и его последователи в европейских институтах выступали за передачу полномочий европейским технократам, которые принимали неполитические решения. Прогрессирующее развитие европейской интеграции при таком подходе определялось бы технократической необходимостью, а не политическим выбором [For a New Europeanism 2017].

Наконец, А. Спинелли и его последователи в социалистических и либеральных кругах разработали федералистскую модель объединенной Европы. Согласно ей, федеральная Европа должна была иметь федеральное правительство, ответственное перед Европейским парламентом (избранным путем общего голосования), федеральную палату парламента, в которую входили бы представители государств-членов, Трибунал справедливости и другие институты, которые бы представляли групповые европейские интересы. Стоит напомнить, что именно концепция федерализма была первой в истории теоретического и идеологического обоснования европейской интеграции. Ее еще в межвоенный период начал обосновывать австриец Р. Куденхове-Калерги в книге «Пан-Европа».

Долгое время европейский проект фактически развивался по логике христианских демократов. Федерализм же рассматривался как слишком амбициозная идея, которая не имела поддержки населения и правительств государств. Только что восстановив государственный суверенитет, страны послевоенной Европы не готовы были им поступаться. Поэтому сначала для интеграции был избрана узкая сфера экономики соседних стран, что получило практическое воплощение в Европейском объединении угля и стали. Сближение государств предлагалось начать с менее чувствительных сфер - экономической, социальной, культурной. Затем интеграция должна была охватить сферу безопасности и внешней политики. Однако последние продолжали оставаться самыми слабыми звеньями европейской интеграции, где решающее слово было за государствами-членами, а роль наднациональных институтов была ограниченной.

Сущность такого подхода к формированию европейского проекта хорошо отражает известный тезис Р. Шумана от 9 мая 1950 г.: «Европу невозможно построить сразу или по определенному плану. Ее надо строить постепенно, через конкретные достижения, которые заложат основы солидарности де-факто» [White Paper... 2017: 4]. То есть, европейская интеграция была задумана как процесс, а не стабильная конструкция. При этом никогда не существовало полного согласия относительно того, к какому результату должен был привести этот процесс. Даже нечеткая формулировка «более тесного союза», что было предусмотрено Римскими договорами 1957 г., выглядит сомнительной [Lehne 2018].

Как следствие, европейский проект сейчас представляет собой неоднозначную доктрину, которая четко не определяет конечный объем полномочий и конституционное строение блока. В отличие от федерации, которая допускает централизацию в ограниченном числе секторов (внешняя политика, оборона, четыре свободы, общий рынок) и полную децентрализацию в остальных сферах, в современном ЕС наблюдается чрезмерная привязанность к централизации, гармонизации и регуляции. Во многих аспектах ЕС уже более централизован, чем большинство федераций в мире. Поэтому граждане государств - членов ЕС воспринимают его как технократическую структуру, которая неблагосклонна к национальным государствам. Современная европейская идея выглядит во многих государствах-членах устаревшей и неприемлемой, что свидетельствует о необходимости ее срочного обновления в соответствии с нынешними реалиями [For a New Europeanism 2017].

Изначально развитие институциональной структуры европейской интеграции ассоциировалось, прежде всего, с изменением учредительных договоров о 
создании европейского сообщества. Однако в течение последних двух десятилетий концептуальная связь между реформированием европейских институтов и изменением договоров была потеряна. С 1990-х гг, когда европейская интеграция стала касаться чувствительных для общественности вопросов, в частности монетарной политики и внутренней безопасности, ратификация в парламентах государств-членов или на всенародных референдумах нового договора становилась все более проблемным вопросом. Подтверждением тому стали негативные результаты голосования на референдумах в Дании по одобрению Маастрихтского договора, в Ирландии - Ниццкого и Лиссабонского договоров, а во Франции и Нидерландах - по одобрению Конституции для Европы. Как следствие, возникло мнение, что нынешние дискуссии об осуществлении реформ в ЕС не могут ставить целью изменение базовых договоров, а обновление ЕС должно происходить в рамках действующих европейских правовых норм [Lehne 2018].

С целью содержательного наполнения дискуссий о реформе ЕС Еврокомиссия 1 марта 2017 г. предложила 5 сценариев будущего развития Европы (ЕС-27, т.е. без Великобритании) к 2025 г. Они содержат широкий выбор путей дальнейшего развития европейской интеграции - от возвращения к состоянию государств-наций до создания европейского федеративного государства [White Paper... 2017].

Если 2-й и 5-й сценарии («Ничего, кроме единого рынка» и «Намного больше сделаем вместе») предусматривают кардинальную реформу ЕC, что потребует внесения изменений в основополагающие договоры, то 3-й и 4-й сценарии («Те, кто хотят большего, делают больше» и «Делаем меньше, но более эффективно») являются модификациями первого («Продолжение деятельности») и попыткой дать ЕС новый импульс. Они развивают концепцию дифференцированной интеграции, которая может служить инструментом имплементации прагматической стратегии интеграции без необходимости пересмотра учредительных договоров.

Сценарий «дифференцированной интеграции» сейчас рассматривается как шанс для ЕС. И хотя различные формы дифференциации реально внедрялись в европейских сообществах еще с начала европейской интеграции в 1950-х гг., именносейчасэта концепция приобретаетособоезначение. Онарассматривается как возможность компенсировать гетерогенное строение государств - членов ЕС и их объективные различия политической волей, делегировать больше суверенитета на наднациональный уровень. Формат дифференцированной интеграции может служить выработке баланса между углублением и расширением ЕС и уже доказал свою способность быть эффективным инструментом в управлении европейским многообразием (Шенген, зона евро, в которых принимают участие не все члены ЕС). Вместе с тем дифференцированная интеграция может привести и к противоположным последствиям: с одной стороны, она будет способствовать лучшему управлению многообразием среди государств-членов, преодолевая тупик в интеграционных процессах, а с другой - может запустить дезинтеграционные процессы. Поэтому дифференциация не должна отождествляться с фрагментацией блока [Tekin 2017].

Дифференцированная интеграция может воплощаться в виде различных подходов, таких как «многоскоростная Европа», «срединная Европа», «Европа переменных геометрий» или «Европа а ля карт». В случае внедрения концепции «многоскоростной» Европы цели и сферы интеграции определены для всех государств-членов, однако лишь определенная группа государств-членов продвигается в направлении их достижения, а другие со временем могут присоединиться к ним. Для них не исчезает такая возможность, но они и не 
обязаны следовать им. «Многоскоростная» Европа может перейти в «срединную» Европу, если отстающие государства-участники не будут способны или не пожелают присоединиться к блоку лидеров интеграции в долгосрочной перспективе, а ядро желающих государств-членов решит внедрять следующие интеграционные цели. Сейчас это пытаются внедрить в рамках экономического и валютного союза. В случае Европы «переменных геометрий» цели и направления интеграции предварительно не определены для всех государств-членов. Это значит, что желающие государства-члены могут продвигаться дальше без согласия других. Это приведет к многообразию интеграционных группировок с разнообразным аккаунтом. Европа «а ля карт» предлагает широкий набор целей и направлений интеграции, каждое государство-член может выбирать их на индивидуальной основе и группироваться с другими. Относительно традиционного процесса расширения ЕС предлагается внедрение концепции ассоциированного членства [Tekin 2017].

Среди всех возможных форм дифференциации преимущество должно быть предоставлено той, которая содержит наименьший риск фрагментации ЕС. Несмотря на это, внедрение концепций «многоскоростной» Европы, Европы «переменных геометрий» или Европы «а ля карт» таит риски активизации дезинтеграционных процессов, даже с учетом того, что подобные прецеденты не наблюдались в прошлом [Martonyi 2018].

Наименьший риск фрагментации имеет юридический инструмент усиленного сотрудничества между государствами - членами ЕС, не создающий раскол между различными группами государств, вовлеченных в разные форматы такого сотрудничества. Этот механизм был впервые предусмотрен в Амстердамском договоре 1999 г. и развит во всех последующих договорах. Главной проблемой было его неприменение [Tekin 2017]. Инструмент усиленного сотрудничества соответствует 4-му сценарию Белой книги о будущем Европы и был воплощен, в частности, при создании Постоянного структурного сотрудничества PESCO в оборонной сфере. Он может быть компромиссом между сторонниками укрепления наднациональных структур и государственного суверенитета, ведь определенные приоритетные области интеграции переходят под управление EC, тогда как другие отрасли будут возвращены в компетенцию национальных государств.

Отрасли, подпадающие под исключительную юрисдикцию EC, а именно торговля и конкуренция, функционирование общего рынка и институциональное строение ЕС, должны быть исключены из процесса дифференцированной интеграции. Это в равной степени касается и вопросов миграционной и внешней политики. Итак, 3-й и 4-й сценарии фактически являются продолжением нынешнего процесса развития ЕС, однако с широким использованием возможностей Лиссабонского договора. Несмотря на объявленные намерения, власть и население государств-членов не готовы к углублению политической интеграции в области миграционной и внешней политики.

Наряду с концепцией дифференцированной интеграции, в научных и экспертных кругах Евросоюза обсуждается возможность построения блока на федеративных началах, чему соответствует 5-й сценарий Белой книги. Однако в этой связи следует отметить, что на сегодняшний день существует ошибочная трактовка понятия федерализма, сводящая его исключительно к передаче избыточных полномочий наднациональным институтам. На самом деле федерализация будет означать укрепление ЕС в ограниченных отраслях: внешней политике, безопасности, экономическом управлении в еврозоне и общем рынке, защите границ и политике убежища. Применение федералистского подхода может помочь преодолеть вызовы управления ЕС и ослабить давление 
от затяжных кризисов, ведь транснациональным вызовам и угрозам было противопоставлено институциональное и функциональное единство ЕС [Ottavio Reho, Rohac 2017].

B европейском контексте федерализм должен отличаться от его воплощения в модели США. В США во время основания государства первично была создана модель «конкурентного федерализма», в котором автономные субъекты управления конкурировали и дисциплинировали друг друга; однако вследствие гражданской войны она эволюционировала в модель «картельного федерализма», где была значительно усилена роль федерального центра. Поэтому США является плохим примером для возможной федерализации Европы. Для последней больше подходит модель аутентичного, децентрализованного и конкурентного федерализма, в котором общие европейские институты придерживались бы общности европейской цивилизации, могли бы укреплять единство общего рынка, осуществлять надзор над федеральной монетарной, внешней и оборонной политикой, защищать равные права всех граждан. Остальные функции должны быть отданы на национальный уровень, гармонизация - сведена к минимуму, а децентрализация - поощрена на всех уровнях [Ottavio Reho, Rohac 2017]. В результате ЕС мог бы лучше приспособиться к современным вызовам и угрозам.

Однако в целом федерализм пока не является пунктом повестки дня реформы ЕС. Данная альтернатива практически не обсуждается на заседаниях европейских институтов. Лидеры ЕС скорее рассматривают модель дифференцированной интеграции в качестве будущего пути развития блока. Ведь идею превращения ЕС в своего рода «Соединенные Штаты Европы» с центральным правительством поддерживают только $30 \%$ граждан стран ЕС, тогда как $41 \%$ отвергают такую идею, а $28 \%$ остаются нейтральными к ней [Raines, Goodwin, Cutts 2017: 38]. Таким образом, можно сделать вывод, что многочисленные кризисы второй декады XXI в. показали низкую институциональную способность ЕС устоять перед подобного рода вызовами и угрозами. Остро встала необходимость реформирования блока в условиях низкого доверия граждан к нему и всеохватывающего кризиса легитимности. Предложенные Еврокомиссией 5 возможных вариантов будущего развития ЕС предусматривают различные перспективы - от движения в направлении европейской супердержавы к ограничению интеграции вопросами общего рынка. Если первый вариант на сегодня выглядит утопическим и имеет низкую поддержку граждан, то последний фактически нивелирует 60-летние достижения европейского проекта. Относительной поддержкой среди элит и граждан государств - членов ЕС пока пользуются сценарии «многоскоростной» интеграции и усиленного сотрудничества, которые в той или иной степени (относительно Шенгена и зоны евро) уже имеют частичное воплощение в нынешней архитектуре ЕС. Будут ли они успешными в будущем или, наоборот, обернутся распадом блока - покажет будущее развитие событий, однако уже сейчас очевидно, что ЕС должен заново выстроить солидарность между членами и восстановить доверие собственных граждан. От достижения этой цели во многом зависит то, переживет ЕС кризис и станет сильнее, или государства-члены последуют примеру Великобритании. Сейчас ситуация напоминает послевоенный период, когда опустошенные войной страны Европы должны были объединиться в противовес влиянию СССР и США. Сегодня ЕС должен восстанавливаться ради противостояния возможному доминированию России и Китая на Европейском континенте в условиях неопределенности позиции США. От этого будет зависеть как судьба самого ЕС и мира на континенте, так и либеральной модели мирового развития, над которой Брюссель в последнее время потерял контроль. 


\section{Список литературы}

Bertoncini Y. 2017. Democratic Crises in the EU: Towards «New Frontiers». Jacques Delors Institute. 14 November. 12 p. URL: http://institutdelors.eu/wp-content/uploads/2018/01/democraticcrisesintheeu-bertoncini-oct17.pdf (accessed 06.07.2019).

For a New Europeanism (ed. by F. Ottavio Reho). 2017. Wilfried Martens Centre. 12 p. URL: https://www.martenscentre.eu/sites/default/files/publication-files/futureeurope-new-europeanism.pdf (accessed 06.07.2019).

Lehne S. 2018. EU Reform: Does Everything Have to Change for Things to Remain the Same. Carnegie Europe. 19 July. URL: http://carnegieeurope.eu/2018/07/19/ eu-reform-does-everything-have-to-change-for-things-to-remain-same-pub-76871 (accessed 06.07.2019).

Martonyi J. 2018. Differentiation, not Disintegration. Wilfried Martens Centre. 15 p. URL: https://www.martenscentre.eu/sites/default/files/publication-files/differentiated-integration-disintegration-future-europe.pdf (accessed 06.07.2019).

Ottavio Reho F., Rohac D. 2017. The Case for a Federal Europe. Wilfried Martens Centre. May. 10 p. URL: https://www.martenscentre.eu/sites/default/files/publication-files/case-for-a-federal-europe.pdf (accessed 06.07.2019).

Raines T., Goodwin M., Cutts D. 2017. The Future of Europe. Comparing Public and Elite Attitudes. Chatham House. 47 p. URL: https://www.chathamhouse.org/sites/ default/files/publications/research/2017-06-20-future-europe-attitudes-raines-goodwin-cutts-final.pdf (accessed 06.07.2019).

Tekin F. 2017. Differentiated Integration. Institute for European Politics, March. URL: http://webcache.googleusercontent.com/search?q=cache:http://iep-berlin. de/wp-content/uploads/2017/03/Funda-Tekin-Differentiated-Integration-OnlinePaper2017.pdf (accessed 06.07.2019).

The Age of Uncertainty. Global Scenarios and Italy (ed. by A. Colombo, P. Magri). 2017. ISPI. 172 p. URL: https://www.ispionline.it/sites/default/files/pubblicazioni/ the_age_of_uncertainty.pdf (accessed 06.07.2019).

White Paper on the Future of Europe. Reflections and Scenarios for the EU27 by 2025. 2017. European Commission. 32 p. URL: https://ec.europa.eu/commission/ sites/beta-political/files/white_paper_on_the_future_of_europe_en.pdf (accessed 06.07.2019).

RYBAKOV Andrei Vyacheslavovich, Dr.Sci. (Pol.Sci.), Professor of the Chair of Philosophy, Moscow Aviation Institute (National Research University) (4 Volokolamskoe Highway, A-80, GSP-3, Moscow, Russia, 125993; rybackov@ rambler. ru)

KWON Daniil Andreevich, Cand.Sci. (Pol.Sci.), Associate Professor of the Chair of Political Science, Moscow Aviation Institute (National Research University) (4 Volokolamskoe Highway, A-80, GSP-3, Moscow, Russia, 125993; docentkvon@yandex.ru)

\section{EUROPEAN INTEGRATION DEVELOPMENT: SCENARIO ANALYSIS}

Abstract. The subject of research in the article is the possible options for the further evolution of the integration process in the European Union (EU). The authors show that the crisis processes in the development of EU institutions have given impetus not only to Euroscepticism, but also to an intensive search for new approaches to the development of European integration. In reality, we are dealing with a complex, ambiguous and even internally contradictory process, which under any circumstances is wrong to depict only in one color, predicting a certain single trend of further development. We are 
talking about a number of possible options for the further evolution of the European integration process. The choice between these options will depend on the level of political volition and creativity of the respective political forces, the ability to think strategically, going beyond the narrow framework of the vision of the present and the ability to analyze the entire complex set of factors, underlying European integration, carefully and in balanced way.

Keywords: European integration, European Union, crisis, development scenarios, differentiated integration, federalization, multi-speed Europe, enhanced cooperation

МАХМУТАЙ Ноэла Мэстан (Албания) - аспирант факультета международных отношений Санкт-Петербургского государственного университета (191060, Россия, г. Санкт-Петербург, ул. Смольного, 1/3, 8 под.; noela1302@gmail.com)

\title{
СОВРЕМЕННОЕ СОСТОЯНИЕ АЛБАНСКО- РОССИЙСКИХ ОТНОШЕНИЙ В ПОЛИТИЧЕСКОЙ СФЕРЕ
}

\begin{abstract}
Аннотация. Современные политические отношения между Тираной и Москвой выстраиваются на стремлении к деловому и конструктивному партнерству, невзирая на разное отношение к некоторым международным проблемам (например, косовский кризис, расширение НАТО на восток, трагические события на Украине, борьба против терроризма). Автор оценивает будущее албанско-российских отношений в целом положительно, отмечая тенденцию к восстановлению культурных и творческих контактов, взаимного доверия, укреплению дипломатических отношений и расширению торгово-экономического взаимодействия.
\end{abstract}

Ключевые слова: албано-российские отношения, расширение НАТО, косовский кризис, укрепление дипломатических отношений, расширение торгово-экономического взаимодействия

$\mathbf{Y}$ ходящие корнями в глубину веков албанско-российские отношения неоднократно проходили фазы расцвета и увядания на протяжении своей более чем 250-летней истории [Албания, албанцы... 2013: 11]. Первое взаимодействие России и Албании датируется серединой XVIII в., когда эти страны объединились в войне против Османской империи. После окончания военных действий тысячи албанцев, первоначально присоединившихся к российской армии, остались жить в России. Но настоящая дружба между Албанией и Россией начинается лишь в XX в. [Лямерошай 2014: 77-78]. После Второй мировой войны в Албании сложился и укрепился коммунистический режим. С 1945 г. Москва была ближайшим союзником Тираны. Отношения между Албанией и Россией во времена коммунистического режима были дружественными: обе страны проявляли большой интерес друг к другу.

Сотрудничество, впрочем, длилось недолго: в 1961 г. произошел открытый дипломатический разрыв между странами по причине идеологического разногласия. Лидер Албании Э. Ходжа открыто критиковал политический курс, выбранный Н.С. Хрущевым. Этот период продолжался почти 30 лет. Дипломатические отношения снова восстановились только после распада коммунистического режима (в 1991 г.), но сотрудничество между двумя государствами не получило должного развития, т.к. обе страны придерживались разных политических ориентаций на международной арене, и их интересы не совпадали.

После распада режима Э. Ходжи в Албании сформировался политический 